\title{
Côme SIMIEN, Les massacres de septembre 1792 à Lyon
}

Préface de Michel Biard, Lyon, Éditions Aléas, 2011, 240 p., ISBN

978-2-84301-318-8, $18 €$.

Jean-Clément Martin

\section{(2) OpenEdition}

\section{Journals}

Édition électronique

URL : https://journals.openedition.org/ahrf/12822

DOI : $10.4000 /$ ahrf.12822

ISSN : 1952-403X

Éditeur :

Armand Colin, Société des études robespierristes

Édition imprimée

Date de publication : 1 juin 2013

Pagination : 186-188

ISBN : 978-2-9083-2789-2

ISSN : 0003-4436

Référence électronique

Jean-Clément Martin, "Côme simien, Les massacres de septembre 1792 à Lyon », Annales historiques de la Révolution française [En ligne], 372 | avril-juin 2013, mis en ligne le 01 juin 2013, consulté le 01 juillet 2021. URL : http://journals.openedition.org/ahrf/12822 ; DOI : https://doi.org/10.4000/ahrf.12822

Ce document a été généré automatiquement le 1 juillet 2021.

Tous droits réservés 


\title{
Côme SIMIEN, Les massacres de septembre 1792 à Lyon
}

Préface de Michel Biard, Lyon, Éditions Aléas, 2011, 240 p., ISBN

978-2-84301-318-8, $18 €$.

\author{
Jean-Clément Martin
}

\section{RÉFÉRENCE}

Côme SIMIEN, Les massacres de septembre 1792 à Lyon. Préface de Michel Biard, Lyon,

Éditions Aléas, 2011, 240 p., ISBN 978-2-84301-318-8, $18 €$.

1 Le 9 septembre 1792, alors que la journée a débuté par un rassemblement des gardes nationaux et de soldats de ligne venus prêter serment sur la plaine des Brotteaux à Lyon, elle s'achève avec l'entrée en force d'une foule dans deux prisons et le massacre de huit officiers et trois prêtres, devant les autorités impuissantes. Dira-t-on que la chose, à défaut d'être banale, était courante? Launay et Flesselle, Berthier et Foulon ont connu ce sort à Paris dès juillet 1789, on pourrait continuer par Belzunce à Caen, Dillon à Lille, Gérard à Lorient, Simonneau à Étampes, avant d'évoquer les pendus de Marseille et de Provence et bien entendu les massacrés de septembre 1792 (pour mémoire, Pierre Caron avait recensé soixante-cinq lieux de tueries et Frédéric Bluche, deux cent quarante-quatre). La Rochelle, où des prêtres réfractaires sont dépecés en mars 1793, prolonge cette litanie de tueries commises par des révolutionnaires et par des contre-révolutionnaires. Les mises à mort des patriotes de Machecoul et du maire de La Roche-Bernard marquent en effet les premiers soulèvements des "vendéens » et des chouans au printemps 1793, avant que la Terreur blanche ne s'installe et se prolonge, jusqu'en 1815, dans la vallée du Rhône et en Provence. Rappelons que les foules émeutières n'avaient pas pu massacrer Calonne ou Lamoignon comme elles en manifestaient l'envie dès 1787-1788 et qu'en avril 1789 les fabricants Réveillon et Henriot avaient échappé miraculeusement à cette destinée. 
2 Les explosions de violences, les massacres populaires, les tueries spontanées, les vengeances incontrôlées, appelons-les comme on veut pour le moment, ont été un des éléments marquants de toute la période et il faut se féliciter, au-delà de toute autre considération, que de jeunes historiens se penchent sur ce genre d'événements qui demeurent toujours délicats à interpréter et à comprendre. Alors que l'opinion, travaillée sans doute par des médias, mais demeurée insatisfaite, se repaitt toujours de ce genre de " détails " scandaleux, il est heureux que les travaux érudits et solidement réfléchis s'attaquent à ces faits en les insérant dans des chaînes explicatives. L'enjeu est là : donner des récits irréfutables, dresser les tableaux précis des contextes et des structures dans lesquels ces événements se sont produits, examiner les légendaires et surtout proposer des grilles d'analyses fortes. Des travaux ont répondu à ces critères, comme, parmi d'autres, les livres de Claudy Valin sur La Rochelle ou la thèse restée malheureusement inédite de Bernard Conein sur septembre 1792. Ce livre entre de plain-pied dans ce petit groupe.

3 Le ton est austère, voire scolaire, accordé à la rigueur de la démonstration. Après une présentation de la question, le récit de la journée est précédé par les circonstances qui ont conduit quelques officiers, démissionnaires mais demeurés encore dans leur corps, à arriver à Lyon avant d'aller aux frontières. Leur situation est paradoxale. Ils sont prêts à quitter l'armée et donc à émigrer, mais encore présents par respect pour le règlement, ce qui les rend éminemment suspects. Il suffira d'une étincelle pour qu'ils soient engloutis dans les tourbillons provoqués par les luttes politiques locales et nationales au moment où la guerre devient une menace directe pour les Lyonnais. On pourra regretter, ici, que l'auteur n'ait pas fait le détour par les insurrections liées aux conflits militaires (de Toulon à Lille en passant par Nancy) qui avaient agité l'opinion nationale et qui expliquaient les états d'âme des officiers. L'exemple de Blondel de Nouainville, étudié par Didier Michel, a montré comment des officiers nobles balançaient entre service de la nation et émigration. Le cas des Lyonnais n'en aurait été que mieux apprécié. Cette dimension, importante, n'est cependant pas essentielle dans le cours de la démonstration qui s'attache à la montée des tensions et des craintes qui débouche au soir du 9 septembre dans l'assaut mené par des groupes mal identifiables contre le fort où se trouvent les officiers. Dans un scénario bien connu, alors que les autorités sont incapables de faire face et sont elles-mêmes suspectées de vouloir soustraire ces hommes à la justice, voire de protéger des coupables, les officiers sont sortis des cellules et tués puis décapités. La soirée se termine avec la mise à mort de trois prêtres dans une prison voisine.

4 Le récit est clair, précis et destiné à faire fond. L'auteur s'engage dans une recherche systématique des causes pour expliquer ce passage à l'acte. Il présente de façon synthétique le contexte économique et social, évidemment mauvais, et insiste à juste titre sur la peur de la famine et sur les rancœurs entre groupes sociaux. Il décrit avec finesse le processus de politisation qui s'est emparé de cette situation, insistant sur la perte de crédit des autorités locales prises dans des jeux de pouvoir, comme sur la peur légitime devant la menace ennemie sur les frontières, si proches, enfin sur le climat culturel particulier qui déshumanise les adversaires. Le tableau pourrait être appliqué à une très grande partie de la France, mais l'auteur en mettant bien en avant les rivalités internes aux Lyonnais et l'état de vide qu'il est possible de relever, justifie son récit. Les "étincelles» ont mis le feu aux poudres accumulées et ont profité de l'état d'esprit politique. Mais plus que la recherche d'une justice «populaire», l'auteur estime qu'il 
s'agit d'un «crime d'amour» (p.173), commis par une foule baignant plus dans l'eschatologie et les millénarismes que dans un univers politique. La référence à Denis Crouzet est justifiée, il aurait fallu la signaler cependant et l'expliciter.

5 Les dernières parties du livre confirment l'approche. Les luttes lyonnaises, pourtant si âpres, ne s'appuient pas sur cette journée, invoquée lorsque tel ou tel acteur politique cherche à nuire à un adversaire en lui imputant une responsabilité. Le légendaire contre-révolutionnaire s'en empare bien et durablement, mais là encore sans lui donner une part exceptionnelle. La journée du 9 septembre 1792 apparait bien devoir être comprise comme le massacre étudié par Alain Corbin à Hautefaye en 1870 (livre cité par l'auteur) dans cette sorte de limbes sociales où des émotions et des vengeances s'exercent en profitant des absences de contrôle et en utilisant l'occasion apportée par des conflits politiques majeurs. C'est le propre de ce que nous avions repéré comme les manifestations des «guerres civiles » qui se jouent sous la trame du politique pendant la Révolution et qu'on retrouve dans les moments de grands déchirements, que l'on pense aux massacres de Jebwane (Pologne) étudiés par Jan Tomasz Gross en 2001, voire aux guerres de l'ex-Yougoslavie. L'horizon anthropologique, bien compris par l'auteur, ouvre des explications extrêmement solides. Reste que ce changement de point de vue, tout à fait profitable, met ainsi les approches traditionnellement politiques, voire politiciennes, en tout cas étroitement idéologiques, dans une perspective critique qui n'est pas tout à fait dans nos habitudes de pensée.

6 Signalons enfin quelques regrets. Quelques coquilles (porte-paroles par exemple) seront à supprimer pour une autre édition. Celle-ci devra garder les cartes très stimulantes mais pas bien commentées qui incitent à continuer l'analyse politicosociale de la ville de Lyon pour relier tous les événements dramatiques aux multiples strates qui en font la richesse et la complexité. Les rapprochements avec les journées de mai et surtout de juillet 1793 sont à peine mentionnés, pas plus que les liens avec l'état des consciences, signalé par les citations des travaux de Paul Chopelin. Lyon et les soubresauts révolutionnaires n'ont pas dit leurs derniers mots mais ce livre apporte une contribution remarquée. 